\title{
Design and performance of an electrical stimulator for long-term contraction of cultured muscle cells
}

\author{
Mario Marotta ${ }^{1}$, Ramón Bragós ${ }^{2}$, and Anna M. Gómez-Foix ${ }^{1}$ \\ ${ }^{1}$ Universitat de Barcelona, Barcelona and ${ }^{2}$ Universitat Politècnica de Catalunya, \\ Barcelona, Spain
}

BioTechniques 36:68-73 (January 2004)

Excitability in muscle cells manifests itself as contractility and may be evoked by electrical stimulation. Here we describe an electrical stimulator device applicable to cells seeded on standard multiwell plates and demonstrate how it effectively stimulates synchronous contraction of skeletal muscle C2C12 cells without damaging them. The electrical stimulator of cultured cells (ESCC) consists of two connection cards and a network of platinum electrodes positioned in such way that each well in a row is uniformly stimulated. The ESCC may produce a range of outputs based on the stimulation parameters it receives from a commercial pulse generator and can be placed in a standard cell incubator, allowing for long-term stimulation as required for biochemical and molecular biological assays. We show that a 90min stimulation of C2C12 myotubes at $50 \mathrm{~V}, 30 \mathrm{~ms}$ of pulse duration, and $3 \mathrm{~Hz}$ of frequency enhances glucose metabolism and glycogen mobilization while oppositely modulating the activity ratio of glycogen metabolizing enzymes. Thus, we demonstrate that long-term electrical stimulation of C2C12 myotubes with the ESCC results in contractility and metabolic changes, as seen in exercising muscle.

\section{INTRODUCTION}

Excitation of muscle or neural cells may be evoked by electrical stimulation. Continuous electrical stimulation of isolated cells in culture provides an excellent model for the study of the ensuing biochemical and molecular changes, excluding the complex set of factors participating in vivo. Excitability in muscle cells causes contractility, and skeletal muscle cells do not contract unless they are stimulated either via the nerve or electrically. Excitation-contraction has many short- and long-term effects on muscle cell functionality. Electrical stimulation in vivo causes immediate effects on glucose metabolism, such as the activation of glucose uptake and glycogenolysis in both fast-twitch and slow-twitch muscles (1-3). However, chronic increases in contractile activity caused by low-frequency electrical stimulation induce a much more profound change in metabolic and transcriptional phenotypes, which leads to the transformation of fast-twitch glycogenolytic muscle fibers into slow-type oxidative fibers (4).
Currently, no device is capable of simultaneously and uniformly stimulating a large number of independent cultured muscle cells so that they will contract over long periods of time. An early attempt to develop such an in vitro model of electrical stimulation was reported by Brevet et al. (5) and later modified by others $(6,7)$. In this setting, cells were cultured in 24-well plates. However, the designed electrical configuration was not easy to standardize because it did not deliver the same current intensity to every well. The device was composed of silver/silver chloride electrodes for the end wells and agar saline bridges for connecting internal wells. Due to their dimensions, saline bridges have lower conductivity and the voltage drop is higher than in culture media. In addition to being time-consuming to produce, disposable bridge electrodes have the disadvantage that solutes diffuse along the agar bridge and alter concentration gradients. Berger et al. (8) described an alternative system adaptable to $175 \mathrm{~cm}^{2}$ tissue culture flasks that included large diameter graphite electrodes parallel to the long axis of the flask cover. This was a fairly inflexible design. First, it required specially designed flasks for each sample of cells, making it difficult to generate a high number of replicates. Second, the large size of the flasks necessitated the preparation of large numbers of cells for each sample condition, which, depending on the source and nature of the cells, was not always feasible. Here we describe an original electrical stimulator of cultured cells (ESCC) suitable for continuous uniform stimulation of a large number of independent wells in standard multiwell culture plates that overcomes the limitations of previously reported systems. We demonstrate its application in the induction of contraction and consequent metabolic changes in $\mathrm{C} 2 \mathrm{C} 12$ mouse skeletal muscle fibers.

\section{MATERIALS AND METHODS}

\section{C2C12 Cell Culture}

$\mathrm{C} 2 \mathrm{C} 12$ cells were cultured in standard 6- or 24-well culture plates. Dulbecco's modified Eagle's medium (DMEM) containing $25 \mathrm{mM}$ glucose and supplemented with $10 \%$ fetal bovine serum (FBS) was used as a growth medium for the myoblasts. Differentiation was induced by incubating cells in DMEM containing $25 \mathrm{mM}$ glucose and supplemented with $10 \%$ horseradish peroxidase (HRP). Fused myotubes (ATCC, Manassas, VA, USA) were used 7 days after the induction of the differentiation. Media and serum were supplied by Invitrogen (Barcelona, Spain).

\section{Preparation and Maintenance of the Electrical Stimulator of Cultured Cells System}

The 6- or 24-well tissue culture plate is placed between two ESCC connection cards, which are attached to a transparent plastic support. Before immersion in the culture medium, platinum wire electrodes are sterilized with $70 \%$ ethanol and subsequently dried under ultraviolet light. The cards are connected by standard electrical cables to a Grass S-48 stimulator (Grass Instruments, Quincy, MA, USA) that generates variable electrical pulses (i.e., pulse duration, $10 \mu \mathrm{s}$ to $10 \mathrm{~s}$; pulse fre- 
quency, $0.01-1000 \mathrm{~Hz}$; and voltage, 10 $\mathrm{mV}$ to $150 \mathrm{~V}$ ). The ESCC system (24 $\mathrm{cm} \times 16 \mathrm{~cm} \times 5 \mathrm{~cm}$ ) is placed inside a standard cell incubator (ThermoForma, Marietta, OH, USA).

\section{Enzyme Activity Assays}

Lactate dehydrogenase activity was measured spectrophotometrically in a reaction mixture containing $0.1 \mathrm{mM}$ $\mathrm{NADH}$ and $0.3 \mathrm{mM}$ pyruvate in $100 \mathrm{mM}$ phosphate buffer, $\mathrm{pH}$ 7.4. To measure glycogen synthase and phosphorylase activities, frozen cell monolayers were scraped in $100 \mu \mathrm{L}$ of homogenization buffer (consisting of $10 \mathrm{mM}$ Tris- $\mathrm{HCl}$, pH 7.0, $150 \mathrm{mM}$ KF, $15 \mathrm{mM}$ EDTA, $600 \mathrm{mM}$ sucrose, $15 \mathrm{mM}$ 2-mercaptoethanol, $10 \mu \mathrm{g} / \mathrm{mL}$ leupeptin, $1 \mathrm{mM}$ benzamidine, and $1 \mathrm{mM}$ phenylmethylsulfonyl fluoride) and sonicated. The samples were centrifuged at $15,000 \times$ $g$, and the supernatants were used for the determination of enzymatic activities. Glycogen phosphorylase activity was determined by the incorporation of $\alpha$-D-[U- $\left.{ }^{14} \mathrm{C}\right]$ glucose 1-phosphate (Amersham Biosciences, Piscataway, NJ, USA) into glycogen in the absence or presence (active form/total activity) of the allosteric activator AMP (5 mM) as previously described (9). Glycogen synthase activity was measured by the incorporation of uridine diphospho-D$\left[\mathrm{U}-{ }^{14} \mathrm{C}\right]$ glucose (Amersham Biosciences) in the absence or presence (active form/total activity) of the allosteric activator glucose 6-P $(10 \mathrm{mM})$ as previously described (10).

\section{Metabolic Measurements}

Glucose was measured enzymatically in a Cobas Fara II autoanalyzer (Roche, Basel, Switzerland) with the GlucoQuant kit (Roche). Lactate was measured enzymatically by standard techniques in the Cobas Fara II autoanalyzer. To measure the glycogen content, cell monolayers were scraped into $100 \mu \mathrm{L}$ of $30 \% \mathrm{KOH}$, and homogenates were boiled for $15 \mathrm{~min}$. Homogenates were spotted onto 31 ET

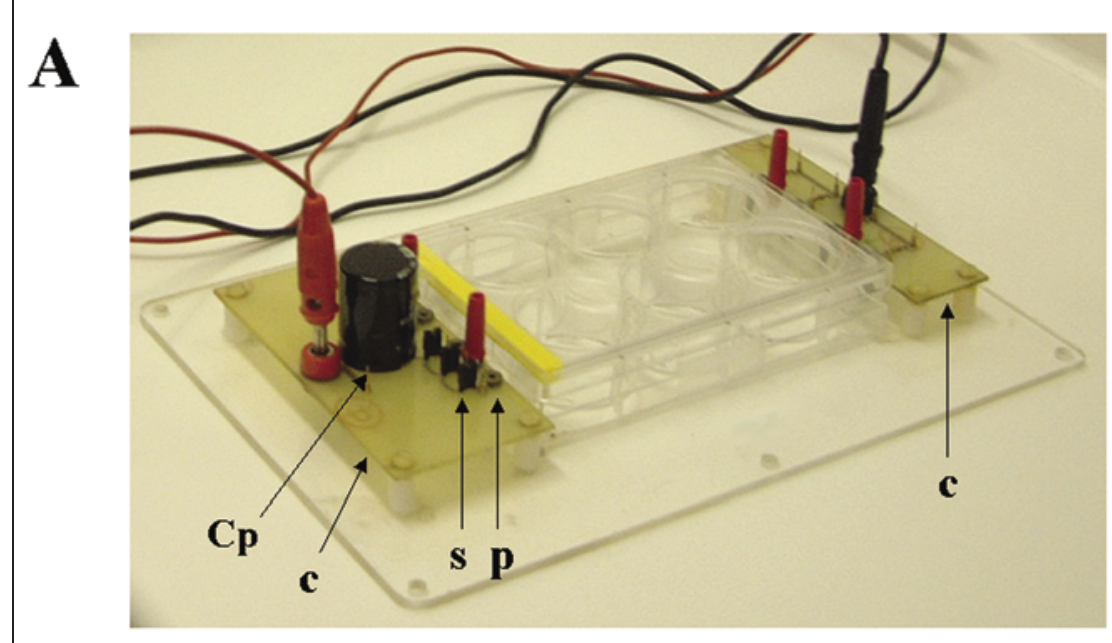

B

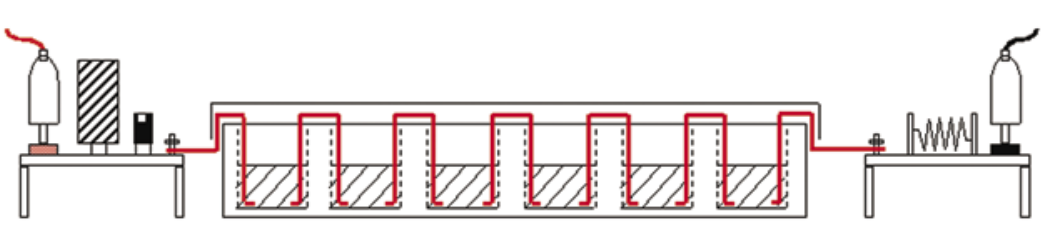

Figure 1. Image of the electrical stimulator of cultured cells (ESCC) system. (A) Global perspective of the ESCC device with the two connection cards (c) flanking a standard 6-well tissue culture plate. The internal components of the connection cards are indicated: the capacitor $(\mathrm{Cp})$, switches (s), and plug sites for end-well electrodes (p). (B) Diagram of the ESCC system showing the design and position of the end-well electrodes connected to the connection cards and the internal bridge-well electrodes connected in series in a row of a 24-well plate.

paper (Whatman, Fungilab, Sant Feliu del Llobregat, Spain), and $\left[{ }^{14} \mathrm{C}\right]-\mathrm{gly}-$ cogen was precipitated by immersing the papers in ice-cold $66 \%$ ethanol. The papers were washed three times in $66 \%$ ethanol and once in acetone and dried at room temperature. Dried papers containing precipitated $\left[{ }^{14} \mathrm{C}\right]$-glycogen were suspended in scintillation fluid for a measurement of the incorporated radioactivity in a scintillation counter (Wallac 1209 Rack Beta; Wallac, Perkin Elmer, Gaithersburg, MD, USA).

\section{Statistical Analysis}

Data are presented as the mean $(\bar{x} \pm$ SEM). A Student's $t$ test was used for statistical analysis. A value of $P<0.05$ was considered statistically significant.

\section{RESULTS AND DISCUSSION}

\section{Description and Operation of the Electrical Stimulator of Cultured Cells}

ESCC consists of two cards that are placed adjacent to the short axis of standard 24- or 6-well tissue culture plates (Figure 1A). These cards are connected to a commercial stimulator (Grass $\mathrm{S}-48$ ) that generates variable electrical pulses. The connection cards distribute the electrical signal to up to six equivalent plug sites. To avoid electrolysis, in one of the cards, a capacitor $(220 \mu \mathrm{F})$ is connected in a series to the circuit to produce a signal with alternating polarity. The electrodes are made of platinum wire $(0.25 \mathrm{~mm} \varnothing)$. The impedance of the platinum electrode $(0.5 \mathrm{~mm} \varnothing)$ at $100 \mathrm{~Hz}$ was $75 \Omega$ at $30^{\circ} \mathrm{C}$. End-well electrodes are connected to the adjacent cards (Figure 1B). The portion of the electrode that is immersed in the culture medium has a semicircular shape that parallels the well walls. The dimensions of the arcs are 1 and $2.5 \mathrm{~cm}$ for 24- and 6-well electrodes, respectively. Internal or bridge electrodes (Figure 1B) are immersed in intermediate wells of every row and connect them, in a series of two by two, so that the plates are divided into equivalent independent rows. Connection of every row may be turned on or off by six switches that are incorporated into the connection 
cards (Figure 1A). Even though the pulse generator creates square-shaped monopolar pulses (Figure 2), the signal emerging from the connection cards is a bipolar pulse, with a quasi-square shape in the positive signal (Figure 2). The signal declines exponentially with time, with a time constant of $400 \mathrm{~ms}$, giving a maximum decline of $7 \%$ for a pulse duration of $30 \mathrm{~ms}$. The negative cycle has an exponential shape and a much lower intensity level, thus the excitation is induced by the positive cycle. The resistance of the culture medium in a 24-well plate filled with $1 \mathrm{~mL}$ was 227 $\Omega$ at $25^{\circ} \mathrm{C}$ and $100 \mathrm{~Hz}$, while that of a 6-well plate filled with $4 \mathrm{~mL}$ was 297 $\Omega$. The homogenous electrical field of every row was confirmed experimentally by voltmeter (Philips, Eindhhoven, The Netherlands) measurements within points $\mathrm{B}$ and $\mathrm{C}$ (Figure 2). When applying $20 \mathrm{~V}$ to the 24 - or 6-well plate filled with saline media, the intensity of the current (root mean square for the

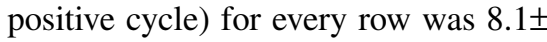
0.1 and $21.6 \pm 0.2 \mathrm{~mA}$, respectively. Considering the impedance values of the electrodes and the saline content in the wells, we calculate that in the 24-well plate, $25 \%$ the voltage output generated by the stimulator decays in electrodes and $75 \%$ in the wells. The electrical field within the well is not homogenous because it is a function of the electrode shape and decreases from the center toward the end of the diameter line perpendicular to the electrical field, with a maximal difference of $13 \%$ and $30 \%$ for the 24- and 6-well plates, respectively. In this diameter line, the estimated current density is $10.2 \mathrm{~mA} /$ $\mathrm{cm}^{2}$ and $14.5 \mathrm{~mA} / \mathrm{cm}^{2}$ for the 24- and 6-well plate, respectively.

To test the applicability of the ESCC, a range of stimulation parameters were applied to $\mathrm{C} 2 \mathrm{C} 12$ mouse skeletal myotubes, including voltages of up to 100 $\mathrm{V}$, pulse durations of up to $100 \mathrm{~ms}$, and pulse frequencies of up to $10 \mathrm{~Hz}$. Observation under a microscope [(Figure 3 and video) (Video is available as supplementary material at the BioTechniques Web site at http://www.BioTechniques.com/ Jan 04/Supplementary Material/ MarottaVideo.html)] revealed that most cells in the monolayer contracted synchronously at voltages higher than $15 \mathrm{~V}$ and pulse durations longer than 1 ms. Stimulation at a frequency of 1 or $3 \mathrm{~Hz}$ caused most of cells in the monolayer to contract synchronously and in accordance with the pace-programmed conditions (see video). At frequencies higher than $10 \mathrm{~Hz}$, no twitch responses were observed.

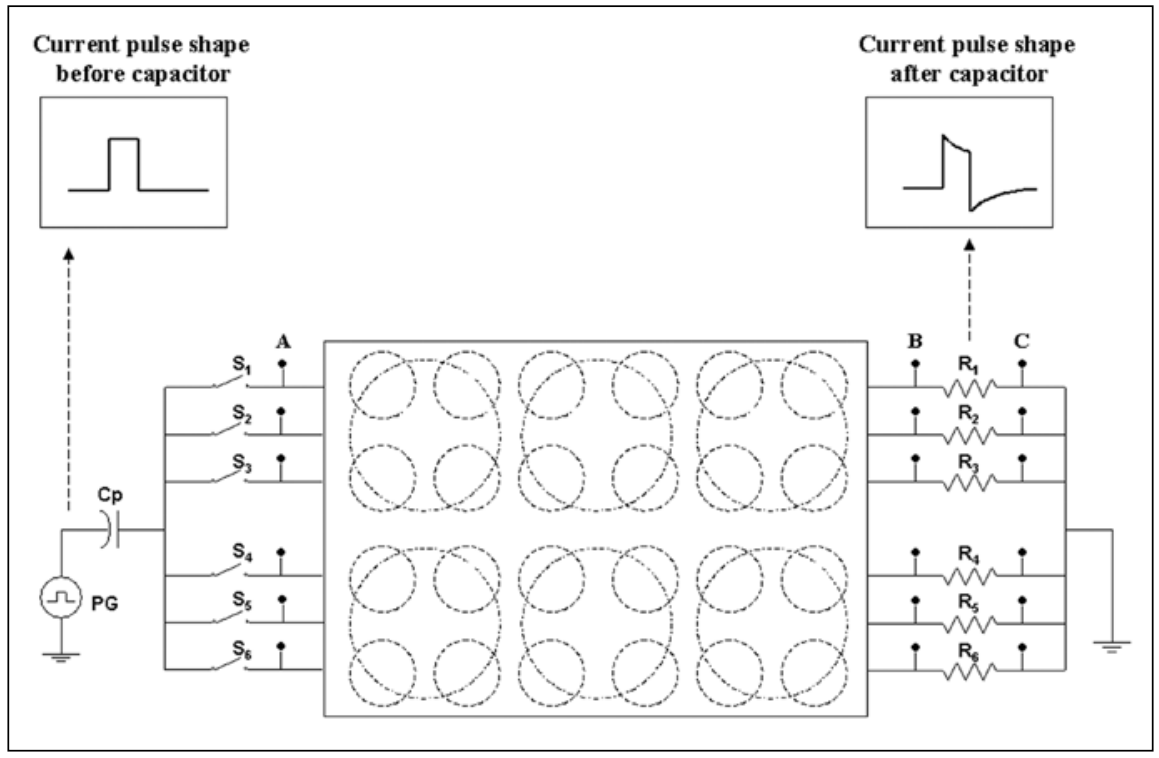

Figure 2. Electrical schema of the electrical stimulator of cultured cells (ESCC) system. PG is the pulse generator. $\mathrm{Cp}$ is the decoupling capacitor, which avoids any direct current flowing through the cell medium. The switches (S1-S6) allow for the selection of the well rows. S1, S3, S4, and S6 are used for the 4-row (24-well) plates, while S2 and S5 are used for the 2-row (6-well) plates. (A) The test points placed next to the switches allow monitoring of the applied voltage, while (B and $\mathrm{C}$ ) the test points connected to the resistors R1-R6 allow the measurement of the resulting electrical current at each well row.
Because the ESCC system is lightweight, it can be placed in a standard cell incubator to maintain the cells in controlled conditions, allowing for medium to long-term stimulation periods. We then evaluated whether long-term electrical stimulation could disturb cell viability. To this end, we used stimulation conditions of $50 \mathrm{~V}, 30 \mathrm{~ms}$, and 3 $\mathrm{Hz}$, which caused effective contraction, and applied them for $90 \mathrm{~min}$ to the cells placed in the standard incubator. We assessed the release of lactate dehydrogenase into the medium at the end of the stimulation period. This activity is used as a marker of alterations in the integrity of the cell membrane. We found no difference in lactate dehydrogenase activity between media from resting and contracting cells $(17.9 \pm 0.6$ and $17.3 \pm$ $0.3 \mathrm{U} / \mathrm{L}$, respectively). These data demonstrated that the device allows for medium to long-term stimulation periods without compromising cell viability.

\section{Regulation of Glucose and Glycogen Utilization in Electrically Stimulated C2C12 Cells}

We then studied changes in glucose metabolism in $\mathrm{C} 2 \mathrm{C} 12$ myotubes following contraction. $\mathrm{C} 2 \mathrm{C} 12$ myotubes were incubated in $25 \mathrm{mM}$ glucosecontaining medium to induce maximal glycogen accumulation, as glycogen is the main metabolic reservoir that provides the energy for contraction (11). The cells were then switched to a 5 $\mathrm{mM}$ glucose medium and electrically stimulated at $50 \mathrm{~V}, 30 \mathrm{~ms}$, and $3 \mathrm{~Hz}$ or left unstimulated for $90 \mathrm{~min}$. We measured the glucose clearance from the medium at the end of the stimulation period. Glucose removal was higher in electrically stimulated $(3.3 \pm 0.2 \mu \mathrm{mol}$ glucose $/ \mathrm{mg}$ protein $/ \mathrm{h}$ ) than in resting cells $(2.1 \pm 0.4 \mu \mathrm{mol}$ glucose $/ \mathrm{mg}$ protein/h).

Subsequently, we examined the glycolytic activity. Lactate production was measured in cells incubated with $5 \mathrm{mM}$ glucose or in cells deprived of glucose during the stimulation period to indirectly evaluate glycogen mobilization. Lactate production in contracting cells was double that found in resting cells, independently of the presence of glucose in the incubation media (Figure 4A), which is consistent with the role 
Table 1. Glycogen Synthase and Glycogen Phosphorylase Activities

\begin{tabular}{|c|c|c|c|c|}
\hline & $\begin{array}{l}\text { Total MGP Activity } \\
\text { (mU/mg protein) }\end{array}$ & $\begin{array}{l}\text { MGP Activity Ratio } \\
\text { (-AMP/+AMP) }\end{array}$ & $\begin{array}{l}\text { Total MGS Activity } \\
\text { (mU/mg protein) }\end{array}$ & $\begin{array}{c}\text { MGS Activity Ratio } \\
\text { (-G6P/+G6P) }\end{array}$ \\
\hline $\mathrm{NCH}$ stimulated & $55.6 \pm 1.4$ & $0.76 \pm 0.01$ & $16.0 \pm 0.2$ & $0.025 \pm 0.001$ \\
\hline Electrically stimulated & $52.1 \pm 2.5$ & $0.61 \pm 0.03^{\star *}$ & $15.1 \pm 0.4$ & $0.038 \pm 0.003^{*}$ \\
\hline \multicolumn{5}{|c|}{$\begin{array}{l}\text { C2C12 myotubes were incubated in a standard incubator at } 37^{\circ} \mathrm{C} \text { for } 90 \mathrm{~min} \text {, with Dulbecco's modified Eagle's medium } \\
\text { (DMEM) containing } 5 \mathrm{mM} \text { glucose and nonstimulated or electrically stimulated with the electrical stimulator of cultured cells } \\
\text { (ESCC) device at } 50 \mathrm{~V} \text {, with a pulse duration of } 30 \mathrm{~ms} \text { and a frequency of } 3 \mathrm{~Hz} \text {. Glycogen synthase (MGS) and phosphorylase } \\
\text { (MGP) activities were measured at the end of the stimulation period as described in the text. Data are shown as means }(\bar{x} \pm \\
\text { SEM) of three independent experiments performed in triplicate. The significance of the differences between nonstimulated and } \\
\text { electrically stimulated cells was }{ }^{\star} P<0.05 \text { and }{ }^{* *} P<0.02 \text {. G6P, glucose } 6 \text {-P. }\end{array}$} \\
\hline
\end{tabular}

of lactate as a physiological marker of muscle contraction. Nevertheless, as expected, lactate release was at least 5fold higher in glucose-incubated cells than in glucose-deprived cells, regard- less of electrical stimulation.

To confirm whether glycogen mobilization was stimulated upon contraction, cell glycogen was prelabeled by incubation with $5 \mathrm{mM}\left[\mathrm{U}-{ }^{14} \mathrm{C}\right]$ glucose
A

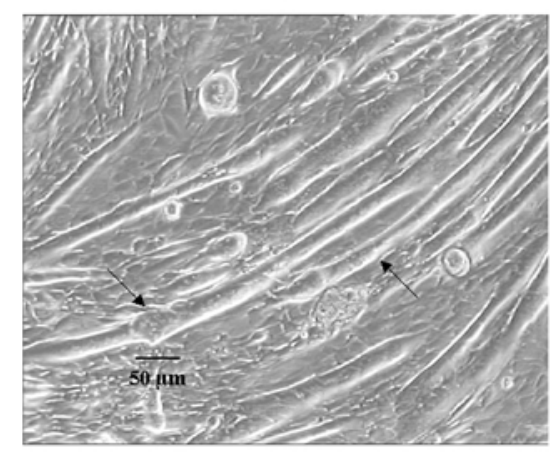

\section{B Contracting cells}

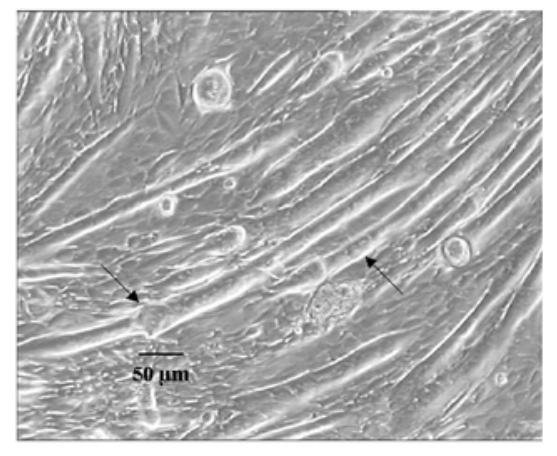

Figure 3. Micrograph of contracting $\mathbf{C 2 C 1 2}$ myotubes. $\mathrm{C} 2 \mathrm{C} 12$ myotubes were stimulated with the electrical stimulator of cultured cells (ESCC) device at $50 \mathrm{~V}, 30 \mathrm{~ms}$ of pulse duration, and $3 \mathrm{~Hz}$ of frequency. (A) Resting cells. (B) Contracting cells. Morphological differences in contracting myotubes are marked by arrows $(\times 200)$.
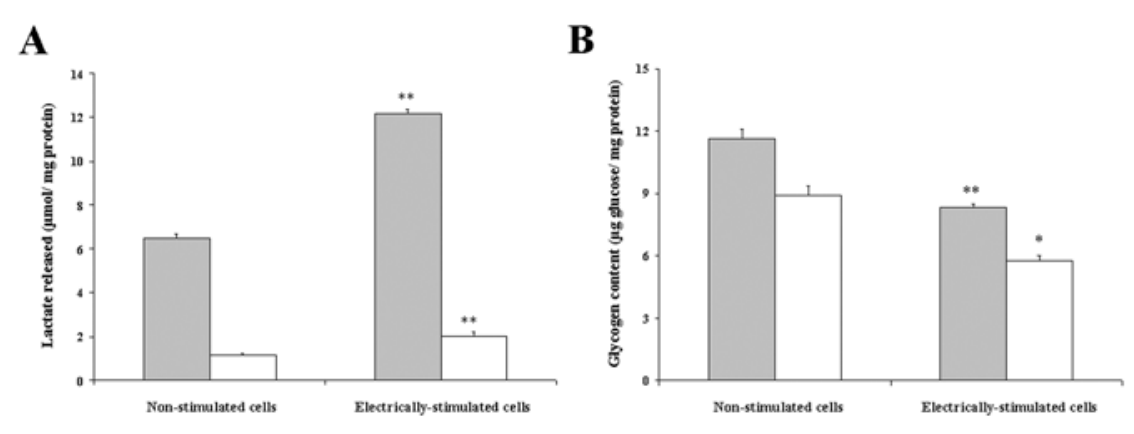

Figure 4. Lactate production and glycogenolysis assays. C2C12 myotubes were incubated in a standard incubator at $37^{\circ} \mathrm{C}$ for $90 \mathrm{~min}$ in media without (white bars) or with $5 \mathrm{mM}$ glucose (gray bars) and were nonstimulated or electrically stimulated with the electrical stimulator of cultured cells (ESCC) device at $50 \mathrm{~V}$, with a pulse duration of $30 \mathrm{~ms}$, and a frequency of $3 \mathrm{~Hz}$. (A) Lactate concentration was measured in the culture medium at the end of the stimulation period. (B) Cells were preincubated for 16 $\mathrm{h}$ with $5 \mathrm{mM}\left[\mathrm{U}_{-}{ }^{14} \mathrm{C}\right]$ glucose $(0.03 \mu \mathrm{Ci} / \mu \mathrm{mol})$ before the 90 -min treatment. The radioactivity associated with glycogen was measured at the end of the stimulation period. Data are shown as the mean $(\bar{X} \pm$ SEM) of three independent experiments performed in triplicate. The significance of the differences between nonstimulated and electrically stimulated cells were $* P<0.005$ and $* * P<0.002$. for $16 \mathrm{~h}$. The cells were then incubated for 90 min with or without $5 \mathrm{mM}$ glucose under electrical stimulation or nonstimulated conditions. At the end of this period, glycogen-associated radioactivity was $30 \%$ and $36 \%$ lower in contracting cells than in resting cells, respectively, with or without glucose (Figure 4B), whereas glucose withdrawal caused a $20 \%$ reduction in nonstimulated cells.

The impact of contraction on the activity of glycogen synthase and glycogen phosphorylase, which are the rate-limiting enzymes for the synthesis and hydrolysis of glycogen, respectively, was examined. The total activity of either enzyme was unaltered by electrical stimulation of glucose-incubated cells (Table 1). Because both enzymes are interconverted by phosphorylation, which modulates their activation state in the opposite direction, we assessed the ratio of active form to total activity. We found that at the end of the 90-min stimulation period, the glycogen synthase activity ratio (with or without glucose 6-phosphate) was 52\% higher in contracting cells than in controls. In contrast, the glycogen phosphorylase activity ratio (with or without AMP) was $24 \%$ lower in contracting fibers.

These results show that electrical stimulation of $\mathrm{C} 2 \mathrm{C} 12$ myotubes by means of the ESCC system induces contractility and metabolic adaptations that imitate those occurring in exercising muscle $(1,2)$. First, in spite of elevated glycogen stores, cell contraction stimulated glucose uptake and enhanced lactate production. Furthermore, we observed that contraction and glucose depletion acted as independent and additive factors to trigger glycogen mobilization. Second, we were able to correlate the stimulation of glycogenolysis with opposing effects on the activation state of glycogen synthase and glycogen phosphorylase, which were activated and inactivated, respectively. This pattern of changes was similar to that observed in vivo after glycogendepleting exercise in the rat (12). In the energy-exhausted muscle, glyco- 
gen synthase is activated while phosphorylase is inactivated, compared to resting or preexercising muscle. Such changes are interpreted as a metabolic adaptation that drives a rapid recovery of glycogen after the termination of contraction.

Here we describe a new device, the ESCC, which is capable of simultaneously stimulating electrically a large number of independently cultured cells over long periods of time. The ESCC overcomes the limitations of previously reported systems. It is adaptable to cells cultured in 6- or 24-well standard tissue culture plates and generates a homogenous electrical field in every row of the culture plate. The ESCC system allows long-term stimulation in standard incubation conditions. Finally, it can produce a range of outputs based on the stimulation parameters it receives from the pulse generator. Therefore, this system may have a broad range of applications in excitable muscle (skeletal, smoth, or cardiac) or neural cells to study ensuing molecular or biochemical changes.

\section{ACKNOWLEDGMENTS}

We gratefully acknowledge Maribel Coca for technical assistance. This work was supported by grant no. SAF2003-04223 from the Dirección General de Investigación, Ministerio de Ciencia y Tecnología, Spain. A.M.G.-F. was a recipient of a fellowship from the Generalitat de Catalunya, Spain.

\section{REFERENCES}

1.Nesher, R., I.E. Karl, and D.M. Kipnis. 1985. Dissociation of effects of insulin and contraction on glucose transport in rat epitrochlearis muscle. Am. J. Physiol. 249: C226-C232.

2.Lund, S., G.D. Holman, O. Schmitz, and O. Pedersen. 1995. Contraction stimulates translocation of glucose transporters GLUT4 in skeletal muscle through a mechanism distinct from that of insulin. Proc. Natl. Acad. Sci. USA 92:5817-5821.

3.Derave, W., H. Ai, J. Ihlemann, L.A. Witters, S. Kristiansen, E.A. Richter, and T. Ploug. 2000. Dissociation of AMP-activated protein kinase activation and glucose transport in contracting slow-twitch muscle. Diabetes 49:1281-1287.

4.Pette, D. and S. Dusterhoft. 1992. Altered gene expression in fast-twitch muscle induced by chronic low-frequency stimulation. Am. J. Physiol. 262:R333-338.

5.Brevet, A., E. Pinto, J. Peacock, and F.E. Stockdale. 1976. Myosin synthesis increased by electrical stimulation of skeletal muscle cell cultures. Science 193:1152-1154.

6.McDonough, P.M., S.L. Stella, and C.C. Glembotski. 1994. Involvement of cytoplasmic calcium and protein kinases in the regulation of atrial natriuretic factor secretion by contraction rate and endothelin. J. Biol. Chem. 269:9466-9472.

7.Xia, Y., L.M. Buja, R.C. Scarpulla, and J.B. McMillin. 1997. Electrical stimulation of neonatal cardiomyocytes results in the sequential activation of nuclear genes governing mitochondrial proliferation and differentiation. Proc. Natl. Acad. Sci. USA 94: 11399-11404.

8.Berger, H.J., S.K. Prasad, A.J. Davidoff, D. Pimental, O. Ellingsen, J.D. Marsh, T.W. Smith, and R.A. Kelly. 1994. Continual electric field stimulation preserves contractile function of adult ventricular myocytes in primary culture. Am. J. Physiol. 266:H341H349.

9.Gilboe, D.P., K.L. Larson, and F.Q. Nuttall. 1972. Radioactive method for the assay of glycogen phosphorylases. Anal. Biochem. 47:20-27.

10.Thomas, J.A., K.K. Schlender, and J. Larner. 1968. A rapid filter paper assay for UDP-glucose-glycogen glucosyltransferase, including an improved biosynthesis of UDP14C-glucose. Anal. Biochem. 25:486-499.

11.Hespel, P. and E.A. Richter. 1990. Glucose uptake and transport in contracting, perfused rat muscle with different pre-contraction glycogen concentrations. J. Physiol. Lond. 427: 347-359.

12.Brau, L., L.D. Ferreira, S. Nikolovski, G. Raja, T.N. Palmer, and P.A. Fournier. 1997. Regulation of glycogen synthase and phosphorylase during recovery from high-intensity exercise in the rat. Biochem. J. 322:303-308.

Received 2 July 2003; accepted 3 November 2003.

Address correspondence to Anna M. Gómez-Foix, Departament de Bioquímica $i$ Biologia Molecular, Facultat de Química, Universitat de Barcelona, Martí $i$ Franquès, 1, E-08028 Barcelona, Spain. e-mail: agomez@bq.ub.es 